\title{
Organisational professional conflict and hybrid clinician managers
}

\section{The effects of dual roles in Australian health care organisations}

\section{Introduction}

Organisational professional conflict has been described as an inconsistency experienced by employed professionals between the requirements of their employer and those of their vocation (Gunz and Gunz, 2002). In other words, professionals such as lawyers, accountants and doctors may experience a discord between their professional values and the organisation's management objectives.

New public management, the main driver of health care organisation reform over the past 20 years (Mickan and Boyce, 2006), promotes the use of management objectives centred on cost reduction and organisational efficiencies in the delivery of healthcare services. New public management now underlies health care management thinking, objectives and practices that may challenge the traditional health care professionals' values of cure and care on which health services have been founded, creating what could be described as a set of tensions between the business of health and the practice of health.

One area of change in health care organisations has been the introduction of the hybrid clinician manager, exemplified by doctors working in combined management and clinical roles (Ferlie and Shortell, 2001; Braithwaite and Hindle, 2001; Fitzgerald and Ferlie, 2000). The hybrid clinician manager role is unlike any other role in a health care organisation. This dual role has a divergent set of objectives that require individuals to navigate between achieving clinical and managerial objectives. However, we suggest that this may not always occur readily for a range of reasons, such as lack of management education and skill, time pressures and personality factors.

Hybrid clinician managers have reportedly experienced internal conflict when tensions manifest, such as when requirements for autonomy and patient care clash with organisational needs or fiscal constraints (Schafer et al., 2002). There is evidence that hybrid clinician managers experience some internal conflict when they see the increasing time commitment of their management role intruding on, what they feel, is their primary job, their clinical role (Dawson, 1995; Harrison, 1999). 
Whilst previous research contends that organisational professional conflict is experienced by hybrid clinician managers, the authors of this work have identified that organisational professional conflict can cause dissonance in other organisational members. This conflict may have implications for the efficiency of a health care organisation. For example, hybrid clinician managers tend to give priority to their clinical work, which can result in delays in decision-making for organisational matters. Delays in organisational decision-making cause tension to other members of the organisation. This extension or duality of organisational professional conflict which causes interpersonal or group conflict in other members of the organisation, to our knowledge, has not yet been researched (Kippist and Fitzgerald, 2006).

We believe it is worth questioning how hybrid clinician managers negotiate dual roles with divergent managerial and professional objectives and what the organisational effects of the hybrid role are. Therefore, we aim to examine the nature of the tensions between hybrid clinician managers' professional values and the health care organisation's management objectives.

\section{Organisational professional conflict}

Organisational professional conflict from the individuals' perspective is experienced by professionals, such as accountants and doctors, when there is a discord between their professional values and the organisation's objectives (Hoff, 1999; Fawcett, 1988; Schafer et al., 2002; Aranya and Ferris, 1984). Individual emotional consequences of conflict may result in low job satisfaction and lowered organisational commitment. Such internal conflict can be demotivating for hybrid clinician managers, is costly to the organisation and it may cause a lowering of quality of performance and high turnover amongst professionals (Schafer et al., 2002; Aranya and Ferris, 1984).

Research on organisational professional conflict originates in the field of accounting. Research indicates that the level of organisational professional conflict is relatively low among professional accountants working in accounting firms. However, this tension increases as professional status within the organisation increases (Aranya and Ferris, 1984). Professional accountants report higher levels of organisational professional conflict when their individual professional autonomy is threatened because of the requirement to be more involved in achieving organisational objectives (Aranya and Ferris, 1984; Schafer et al., 2002). Whilst accounting has largely provided a platform for the investigation of organisational professional conflict, 
the literature lacks reference specifically to organisational professional conflict experienced by members of the medical profession.

\section{Hybrid clinician managers}

Hybrid clinician managers have expert clinical knowledge, manage their professional colleagues, other health care professionals and organisational processes in their departments (Dopson et al., 2002; Fitzgerald and Dufour, 1998; Fitzgerald and Ferlie, 2000; Rees, 1996; Forbes and Prime, 1999; Lopopolo et al., 2004; ledema et al., 2003). The challenge for clinical specialists is to manage dual professional roles within the organisational context (Allen, 1995).

Hybrid clinician managers have an important role in the health care environment, as they are at the intersection of the clinical and managerial domain within the health reform agenda. This could be described as being at the intersection of the practice of health and the business of health. Braithwaite (2004) identifies hybrid clinician managers as having five (5) principal modes of operating: managing change; making decisions and resolving problems; developing self and others; trying to meet the goals and targets of the organisation; and attending to structural and hierarchical matters. These modes of operating are used to meet the primary pursuits of their managerial role: financial, people, organisational management and customer orientation. In other words, hybrid clinician managers must develop various management behaviours to manage the immediate day to day issues of their department.

The role of the hybrid clinician manager is in many ways paradoxical. The hybrid clinician manager's role was developed to focus on the business of the health care organisation by leading the required and appropriate improvement of effectiveness and efficiency of clinical service provision (Degeling et al., 2001). However, hybrid clinician managers appear to spend less time on the secondary pursuits of management such as data, quality and process management, strategic planning and external relations. These secondary pursuits can have long term advantages for the health care organisation and may have possible benefits of cost effectiveness and organisational efficiency of clinical service provision (Braithwaite, 2004). It could be surmised that the role of the hybrid clinician manager may not bring the proposed organisational benefits to the health care organisation that has been initially sought, given the lack of time spent on long term organisational issues that could benefit clinical services and the health care organisation overall. This highlights potential 
organisational conflict where possibly, due to lack of time or managerial skills, the hybrid clinician manager is unable to meet management objectives.

Hybrid clinician managers appear to have both vertical and horizontal conflicting organisational demands and pressures (Glouberman and Mintzberg, 2001; Braithwaite, 2004). Although hybrid clinician managers appear to have some degree of power vis-à-vis their professional subordinates, this group of clinicians expect the hybrid clinician manager to represent them and their interests, which include lobbying for more resources. In addition, there is accountability required from hybrid clinician managers from above, such as corporate level executives and other powerful stakeholders (Braithwaite, 2004). Their expectation of the hybrid clinician manager is to control their own clinical work, and to run efficient and cost effective health care services. Further, hybrid clinician managers compete with their colleagues from other clinical departments for resources, attention and position. Clearly hybrid clinician managers are embedded in a web of complex and pressurised relationships which adds to the complexity of this role, and are a source for organisational professional conflict.

Organisational professional conflict and the complexities of health care management

Glouberman and Mintzberg (2001) introduced an integrative framework for viewing the four worlds of health care. "Cure" focussed on doctors' interventions with patients, "care" focussed on the coordination of care of patients by nurses; "control" through administrative hierarchy and "constraint" by the formal boards or other hierarchical authorities of the hospital. The cure and care domains can be understood as the "practice of health", and the control and constraint domains represent the "business of health". Whilst Glouberman and Mintzberg's model shows clear divides between the worlds and domains, we suggest that the divides or boundaries between each are far from defined and clear. Due to different roles and relationships between the actors in the organisation, boundaries are fuzzy and at times more difficult to identify than is suggested by Glouberman and Mintzberg.

Clearly, both the organisation and hybrid clinician managers' share some values and objectives. This is particularly the case in the practice of health and the care of the patient. Both the health care organisation and the hybrid clinician manager see the patient as being the core of their work practice and needing the best possible care. However, one area where their objectives may diverge is in the business of health, 
where management decisions, driven by cost reduction and organisational efficiency may be seen by some hybrid clinician managers as compromising the quality of delivering patient care and conflicting with their professional values. This suggests that the relationship between organisational and professional commitment for hybrid clinician managers is complex, and fundamentally compromised, both in principle and practice.

\section{Organisational professional conflict and role theory}

Examining role hybridity requires a greater understanding of how role theory applies in the context of health. The introduction of the hybrid clinician manager was designed to bring two distinctive roles together under the assumption that combining professional and managerial roles helps align organisational goals and professional practice (NSW Health, 2000).

Classical organisational role theory focuses on the roles that individuals enact in a social system that are pre-planned, task oriented and hierarchical, and therefore, form a vital function in the achievement of organisational goals (Biddle, 1986). Work roles must be decided by the organisation and adopted by each individual employee in order for an organisation to function effectively as a goal oriented social entity (Katz and Kahn, 1966). We can assume that the employee confers and accepts a role that is reflective of the organisation's culture and norms of behaviour. It also means that for the organisation to function effectively and efficiently the role must be effectively communicated, fully understood and accepted by its employees (Katz and Kahn, 1966).

Changes in human resource management policies and ideologies under new public management thinking have seen workplaces increasingly require employees to multi task which involves employees accepting pluralist roles within the workplace (Lindbeck and Snower, 2001). However, classical organisational role theory indicates that performing multiple roles can be problematic to employees as this becomes less clear (Smithson and Stokoe, 2005). Multiplicity of roles affects role expectations and changes associated role behaviours within a person. In addition, it changes the expectations from colleagues and superiors (Jackson and Sullivan, 1990; Coverman, 1989; Katz and Kahn, 1966). These demands may result in employees choosing between their roles, compromising the behaviours expected in the role or withdrawing from the situation entirely (van de Vliert, 1981). 


\section{Barriers to negotiating duality of roles}

The role of a hybrid clinician manager is complicated and there are many aspects that need to be negotiated across both the managerial and the clinical tasks. Organisational issues such as operational overload, internal management problems, financial constraints and lack of resources have been identified by hybrid clinician managers as barriers that prevent them from undertaking their managerial work (Dawson, 1995). This suggests tension between their ability to be effective in their managerial role and to be available in their clinical role. In addition, whilst hybrid clinician managers did not mention that clinical work was interfering with managerial tasks, they did identify that managerial tasks interferes with their clinical work. This may indicate a preference for clinical work.

There are also challenges that arise from dual clinical and managerial roles due to a lack of management education and training. These include problems associated with professional identity such as having a "clinical" view of management (ledema et al., 2003; Fitzgerald and Dufour, 1998), practicing individualistic decision making (Ashmos et al., 2002), lack of awareness of others' roles in the organisation (Ormrod, 1993) and poor communication with fellow team members (Lopopolo et al., 2004).

Some hybrid clinician managers report that their poor understanding of the philosophies of organisational management and lack of management training, impedes organisational strategic planning (King et al., 2004; ledema et al., 2003). Thus, it appears that although hybrid clinician managers recognise their need for management education, they do not necessarily take action by undertaking management education. The lack of management education also means that in a management team environment, hybrid clinician managers are the least qualified to make managerial decisions. The lack of managerial qualifications held by doctors, who are also managers, is confirmed by research undertaken by Fitzgerald (2002). She found that hybrid clinician managers have significantly less management training than other professionals who are managers, for example nurse managers.

The lack of interest in management as a chosen path, as well as the view that managerial tasks interferes with clinical work, supports the notion that hybrid clinician managers see themselves as doctors first, and managers second. This is in line with previous research that established that doctors do not necessarily see management as a career path, rather it was confirmed that many hybrid clinician managers take a 
hybrid clinician manager role to prevent others from occupying it (Kippist and Fitzgerald, 2006).

The context in which hybrid clinician managers undertake their work can also be a barrier to perform the dual role. A clinician's role can be unpredictable. Being called away to a medical emergency is not something that can be planned into a working day and will interrupt how and when managerial work is attended to. On the other hand, being called away to a medical emergency may also be seen as a release by the hybrid clinician manager from their managerial role. Some hybrid clinician managers may feel more comfortable in their clinical role, and if they have a deficit in management education they may be more likely to struggle with the managerial component (Kippist and Fitzgerald, 2006). Feeling more comfortable in a clinical setting, hybrid clinician managers may prioritise their clinical tasks over their managerial tasks. That choice may also be driven by the difference between their professional values and beliefs of cure and care over the organisation's mission of cost reduction and business of health.

We have identified several barriers to the effectiveness of the role of hybrid clinician manager such as time, lack of management education, lack of interest and the unpredictability of the clinical role impinging on the managerial responsibilities. These barriers may result in the hybrid clinician manager prioritising their roles. If the hybrid clinician manager leaves their managerial tasks to attend to clinical tasks, other team members working with the hybrid clinician manager will experience tensions to get their tasks done. This highlights another potential area of organisational professional conflict; that is, the conflict experienced by other members of the health care organisation.

\section{Methodology}

This research is based on fieldwork conducted in a large teaching hospital in New South Wales, Australia. The purpose of this project was to evaluate a clinical leadership development program run for the cancer therapy centre between early 2003 and 2005. The evaluation of this program was seen as important for developing similar programs and may be a valuable tool in other clinical management areas used to support staff through the change process in the Area Health Service. 
The main source of data in the study came from 14 interviewees. The research participants comprised of some of the clinical leadership development program participants (7), their immediate staff (3), the clinical leadership development program facilitator (1), and senior managers of the hospital (3).

The researchers used semi-structured interviews and observation of interactions between team members at several team meetings. The interview questions for the research participants focused on what they perceived to be the effects of the clinical leadership development program on themselves, the cancer therapy centre and the hospital. The questions centred on the themes of the program's need, content, outcome and future.

Each interview was audio-taped and transcribed verbatim. QSR N-Vivo ${ }^{\circledR}$ software was used to aid detailed coding and analysis of the collected research material, facilitating the interpretation process. Through a reflective, iterative process, theme content was interrogated to explore relationships between and within the themes.

Other data collection techniques were used to supplement the interviews. These included the review of a range of internal documents and management correspondence, annual reports, business plans, organisation charts and strategic plan. Direct observation of staff at meetings and office activity in the context in which they work was also employed. However, these are not reported in detail here, Instead they form part of the context and background against which the results are presented.

\section{Limitations}

In addition to methodological limitations associated with collecting, analysing and presenting qualitative data, such as small number of interviewees, context and time limitations, the research was originally designed to evaluate the effectiveness of a specific clinical leadership program. This paper relates to organisational professional conflict, which was a theme that emerged from the data collected through the research. We believe that organisational professional conflict is experienced by members of the health care organisation and has lead the authors of this paper to identifying this area as a foundation for a larger study in the future. 


\section{Analysis and interpretation}

For the most part the participants in this study spoke about their own experience in being part of the clinical leadership development program and what affect it had on their role as a manager in their department. However, as the participants discussed their experience of undertaking the clinical leadership development program, a theme of conflict and frustration emerged from those working in a hybrid clinician role as well as those working with the hybrid clinicians.

We present quotes from our discussions relevant to the theme of this paper and interpret them under the following headings: Recruitment of the hybrid clinician manager; Challenges experienced in the role; and Organisational professional conflict.

\section{Recruitment of the hybrid clinician manager:}

Clinicians don't take on a dual role because they see it as an attractive role or as part of their career path. Most hybrid clinicians take the role reluctantly. As one stated:

"It needed to be an internal appointment and basically none of the others wanted to do it. They all wanted me to do it. We discussed it by mutual agreement rather than anything else. I expressed that I didn't feel ready, but I got it anyway." (Hybrid Clinician Manager \#1)

Another hybrid clinician commented::

"Doctors get into management roles often by default and it's often vague what they are supposed to do." (Hybrid Clinician Manager \#2)

Another hybrid clinician manager mentioned that taking on the role prevented someone else from getting the role. There was no discussion from the hybrid clinician managers about who might be the best person for the role or who had the appropriate management education or experience for the position. In many ways there was a sense that this was not necessarily an important undertaking. It appears that a key issue was finding someone who was prepared to take it on. These statements indicate that the hybrid role, as seen by the clinicians themselves, is not part of a clinician's career development. This is reinforced by what appears to be lack of succession planning and recruitment process for the role. 
There was also no evidence of the human resources department being involved in the recruitment of the hybrid clinician managers in this department. Further, when asked, the hybrid clinician managers said they did not have a job description for the dual role. However, lack of involvement by human resources department and having no job description gives the hybrid clinician managers fewer boundaries in exercising power and autonomy. The clinical workforce can select who they want for the role and lack of job descriptions allows freedom in the role to do or not do as incumbents see fit.

Nevertheless, according to government who instigated the role, the hybrid clinician manager appears to have an important place in health care organisations. The role was developed to focus on the business of health and bring improvements and efficiencies in clinical services (Degeling et al., 2001). However, in this particular context, the dual role does not appear to be important to the clinicians or the organisation, indicated by the lack interest in role content and the lack of recruitment process.

\section{Challenges experienced in the role}

The role of the hybrid clinician manager is complex bringing challenges to the dual clinical and managerial components. The hybrid role has developed into a more facilitative function whereby clinical and management responsibilities are recognized as being essential to achieving best practice (Fitzgerald et al., 2004). However, this research has identified challenges that the individual hybrid clinician manager experiences.

The following are comments from two hybrid clinician managers about starting a management development program.

"........I was a very reluctant leader, because I am a medical doctor. We have no formal training in management.." (Hybrid Clinician Manager \#3)

This hybrid clinician manager did not see herself as an organisational leader because she was a doctor. This statement indicates there is an underlying assumption that you can lead when you have the knowledge and skills to do so. Health care organisations have doctors in medical leadership roles, we can presume, but for this hybrid clinician manager, the reluctance as an organisational leader is linked to having no formal management training. 
"I have basically come from being at University to being a doctor in my own right, to being a specialist I have not had 5 minutes of management training let alone a devoted year. I am expecting it to be a help with some of my staff issues." (Hybrid Clinician Manager \#1)

This statement indicates this clinician does not see a management role as part of a clinician's career path. Participant hybrid clinician managers in this research were highly trained and skilled in their clinical fields. Their dual role complicates relationships within the health care organisation. Hybrid clinician managers are managed from above with expectations about budgets and efficiency, they manage their peers below, requiring sophisticated people skills and they often compete for resources with peers in other departments (Braithwaite, 2004).

Therefore, the hybrid role requires a range of skills and knowledge drawn traditionally from the business of health. Knowledge and understanding of budgets and forecasts for their department; people skills required to manage subordinates; and lobbying and political skills needed for accessing a greater share of resources are not part of their clinical training.

From these statements it appears that participant hybrid clinician managers recognise having some management education or training would help them gain knowledge and skills they require in their managerial role. The hybrid clinician manager, who identified to need for assistance with staff issues, indicated a need for increased performance management knowledge and skills. For him it was as much about knowing about performance management policies within the health care organisation as it was the skills required to deal with his staff.

Doctors and managers have different discourses and different ways of understanding health care organisations. Managers have the language of the business of health centred on cost reduction and efficiency. Doctors have the language of the practice of health focussing on individual patient care. A hybrid role requires an understanding of both of these discourses, a level of comfort in both spheres, and a capacity to bridge the gaps.

However, not all hybrid clinician managers see management training or education as important. One hybrid clinician manager commented: 
"I was so busy here; I really didn't want to do it as it was going to be such a huge time commitment." (Hybrid Clinician Manager \#4)

Time to devote to management education or training is not the only challenge. Juggling both the clinical and managerial roles has implications for other members of the department and therefore needs to be negotiated within the wider team. One interviewee commented:

"Well there is an agreement amongst the group that I see less patients than others. But it is not by a long way, I still do 2 days of clinical work a week and a day of research per week. You have to balance it." (Hybrid Clinician Manager \#1)

This statement indicates that clinicians do not favour taking on full time management roles. Many hybrid clinician managers juggle several roles. They do not wish to be seen as a "traitor" by their medical peers (Hoff, 1999).

However, when a clinician takes on the dual role of a hybrid clinician manager it is not only their role that changes; their expanded role also affects other members of their team. For example, in the last quote, the hybrid clinician manager implies that his managerial role increases the workload of other clinical members in the department. This statement may also suggest the role of the hybrid clinician manager is attractive to some clinicians as it allows them more autonomy, decreasing their clinical workload and having a broader range of tasks and responsibilities in the health care organisation.

With the introduction of health care reforms and the push for cost reduction and organisational efficiency there is a growing realisation within the clinical field that economic decisions impact on clinical work. Hence, playing a part in organisational decision making has increasing importance for clinicians. Hybrid clinician manager's roles may become more attractive to some. However, as managerial responsibility increases there is likely to be more conflict and frustration with the lack of autonomy.

"My feeling at the moment is that there are far too many micro managers. Everyone feels a sense that they want to be involved in the decision making process. Quite honestly I need permission off seven different people. With anyone of them being able to block from going anywhere. And that just creates frustration on my part and a feeling that I couldn't be bothered." (Hybrid Clinician Manager \#1) 
Or as one hybrid clinician manager pointed out, they have little control over their budget.

"... we don't have any control over our budget, we try, they try and give us responsibility then they try to blame us." (Hybrid Clinician Manager \#5)

If hybrid clinician managers are attracted to the dual role because they believe it would give them more autonomy and power within the health care organisation, and this is not realised, then inevitably they may experience levels of tension when this is not realised.

\section{Organisational professional conflict}

As illustrated in the comments above, the role of the hybrid clinician manager comes with degrees of individual internal conflict. However, tensions among other members of the organisation were also observed. We suggest that this tension may have implications for the efficiency and cost reduction of the health care organisation as it takes the individual's focus and time away from their clinical and managerial duties.

"The time spent in our Executive meetings dealing with the tensions and sometimes outright anger between the doctors, because they are fighting over (clinical) resources is quite ridiculous." (Non Clinician Executive member)

Paradoxically, the hybrid role was developed to lead improvement in the effectiveness and efficiency of clinical service provision and to bridge organisational frictions. However, in this group of hybrid clinician managers, much time was wasted resolving interpersonal conflicts. Team meetings became a source of tension to all involved, were poorly attended or decision-makers left during the meeting. On one occasion, the Director's pager went off and he left the meeting stating:

\section{"Excuse me, I have to go and do some real work." (Hybrid Clinician Manager \#6)}

The Director was a hybrid clinician manager. It was clear that his "real work" was to do direct patient care. This statement indicates that clinicians who take on managerial roles see their clinical role as their "profession" and legitimate career (Fitzgerald and Ferlie, 2000; ledema et al., 2003; Mickan and Boyce, 2006). However, the team members who remained at the meeting were left expressing disappointment that the Director had left. They were unable to make any decisions 
without the director's mandate. Thus, role duality can cause both organisational professional conflict in the person occupying the hybrid clinician's role, as well as the rest of the team.

\section{Discussion}

The objective of this paper was to examine conflict and tensions between hybrid clinician managers' professional values and the health care organisation's management objectives. Our analysis supports previous literature on the individual's experience of organisational professional conflict. The literature on organisational professional conflict shows a discord between a professional's values and beliefs and their organisation's management objectives, where individuals have been shown to experience some form of conflict when working in hybrid professional roles (Gunz and Gunz, 1994; Aranya and Ferris, 1984).

A widely articulated objective of health care organisations is now one of cost reduction and organisational efficiency which has been introduced through new public management economic rationalism and competitive reforms that challenge traditional managerial and professional cultures on which health services have been founded (Mickan and Boyce, 2006). This friction appears to be due to a lack of integration of the business of health into the practice of health. One solution to integrate clinical and managerial work was the introduction of hybrid clinician managers.

Dual roles bring with them challenges to those working in them, particularly where there may have been little interest in the role as a career path, or lack of management education to support the role. Hybrid clinician managers must constantly negotiate between the two distinct roles, which is a major challenge for them. We argue that the role of the hybrid clinician manager may not be the most effective role for the health care organisation.

In the next stage of our research we are examining organisational professional conflict experienced by other members of the health care organisation, who deal with the effects of hybridity of the managerial and clinician's role. It is our belief that the role of the hybrid clinician manager leads to interpersonal conflict. This conflict may occur when hybrid clinician managers choose their clinical role over their managerial role, leaving the managerial functions in a vacuum. We are also examining if this 
conflict, experienced by members of the health care organisation, impedes organisational processes and decision making.

This ongoing research is significant on several levels. Socially, interpersonal conflict can have negative effects both on the individual and other organisational members. This is not to say that organisational professional conflict is always negative. The business of health may be well served by some professional anchoring, especially if there is an apparent shift from a care paradigm (professional values surround the care of patients) towards a neoliberal paradigm (management objectives around meeting financial targets).

Politically, the role of the hybrid clinician manager can be seen to be at the intersection of the business of health and the practice of health. For the health care organisation, the role of the hybrid clinician manager is a way of bringing an understanding from doctors to managerial issues. Researching the political dynamics of this role will involve gaining an understanding of the experience of the hybrid clinician manager managing up, down and across boundaries.

Economically, the effect of the role of the hybrid clinician manager is worth researching given that health care organisations continuously search for efficiencies and push for cost reduction. However, forcing doctors to be more organisationally responsible by creating hybrid clinician manager roles may not be the most efficient or cost effective way to manage health care organisations. As we have seen in this research, role ambiguity can cause organisational professional conflict in both the occupant of the role, as well as the other team members.

Therefore, it is worth questioning how hybrid clinician managers negotiate the managerial and clinical roles, in order to understand the effects on the health care organisations. 


\section{References}

Allen, D . (1995) "Doctors in management or the revenge of the conquered: The role of management development for doctors", Journal of Management in Medicine, 9, 44.

Aranya, N. \& Ferris, K.R. (1984) "A Reexamination of Accountants' OrganizationalProfessional Conflict", The Accounting Review, LIX.

Ashmos, D. P., Duchon, D., McDaniel, R. R. \& Huonker, J. W. (2002) "What a Mess! Participation as a simple managerial rule to "Complexity" organisations", Journal of Management Studies, 39.

Biddle, B. J. (1986) "Recent developments in role theory", Annual Review of Sociology, 12, $67-92$.

Braithwaite, J. (2004) "An empirically-based model for clinician-manager's behavioural routines", Journal of Health Organization and Management, 18, $240-261$.

Braithwaite, J. \& Hindle, D. (2001) "Acute health sector reform: An analysis of the Australian Senate's proposals", Australian Health Review, 24.

Coverman, S. (1989) "Role, overload, role conflict and stress: addressing consequences of multiple role demands", Social Forces, 67, 965 - 82.

Dawson, Sandra. Mole, Veronica. Winstanley, Diana \& Sherval, Jim. (1995) "Management, Competition and Professional Practice: Medicine and the Marketplace", British Journal of Management, 6, 169 - 181.

Degeling, P., Kennedy, J. \& Hill, M. (2001) "Mediating the cultural boundaries between medicine, nursing and managmeent - the central challenge in hospital reform", Health Services Management Research, 14, 36 - 48.

Dopson, S., Fitzgerald, L., Ferlie, E., Gabby, J. \& Locock, L. (2002) "No magic target! Changing clinical practice to become more evidence based", Health Care Management Review, 27, 35-48.

Fawcett, T. (1988) "O.P.C. Organisational Professional Conflict", Australian Accountant, 58, 93.

Ferlie, E. \& Shortell, S. M. (2001) "Improving the quality of health care in the United Kingdom and the United States: A framework for change", The Milbank Quarterly, 79, 281.

Fitzgerald, J.A. (2002) Doctors and Nurses Working Together: A Mixed Methodology in the Construction of Changing of Professional Identies, University of Western Sydney, Sydney.

Fitzgerald, J. A., Lum, M. \& Kippist, L. (2004) "Operating theatre bottlenecks: how are decisions about emergency theatre schedules made", paper presented at 5th International CINet Conference, Sydney, Australia.

Fitzgerald, L. \& Dufour, Y. (1998) "Clinical management as boundary management a comparative analysis of Canadian and UK health-care institutions", Journal of Management in Medicine, 12, 199.

Fitzgerald, L. \& Ferlie, E. (2000) "Professionals: Back to the future?", Human Relations, 53, 713-740.

Forbes, T. \& Prime, N. (1999) "Changing domains in the management process Radiographers as managers in the NHS", Journal of Management in Medicine, 13, 105.

Glouberman, S. \& Mintzberg, H. (2001) "Managing the Care of Health and the Cure of Disease- Part 1: Differentiation", Health Care Management Review, 26, 56-69. 
Gunz, H. P. \& Gunz, S. P. (1994) "Professional/organizational commitment and job satisfaction for employed lawyers", Human Relations, 47, 801 - 320.

Gunz, H. P. \& Gunz, S. P. (2002) "The lawyer's response to organizational professional conflict: an empirical study of the ethical decision making of inhouse counsel", American Business Law Journal, 39, 241.

Harrison, Rosemary \& Miller, Susan. (1999) "The Contribution of Clinical Directors to the Strategic Capability of the Organization", British Journal of Management, 10, 23 - 39.

Health NSW, (2000) Report of the NSW Health Council: A better health system for NSW 03/2000., Sydney, NSW: NSW Health.

Hoff, T. J. (1999) "The Social Organization of Physician Managers in a Changing HMO", Work and Occupations, 26, 324-351.

Iedema, R., Degeling, P., Braithwaite, J. \& White, L. (2003) "It's an Interesting Conversation I'm Hearing': The Doctor as Manager", Organization Studies, 25, 15-33.

Jackson, L. A. \& Sullivan, L. A. (1990) "Perceptions of multiple role participants", Social Psychology Quarterly, 53, 274 - 82.

Katz, D. \& Kahn, R. L. (1966) The Social Psychology of Organisations, Wiley, New York, N.Y.

King, D., Kerridge, R. \& Candsell, D. (2004) "RNS \& RHS surgical services review".

Kippist, L. \& Fitzgerald, J. A. (2006) "The value of management education for hybrid clinician managers", paper presented at ANZAM, Rockhampton, Queensland, Australia.

Lindbeck, A. \& Snower, D. J. (2001) "Centralized bargaining and reorganized work: are they compatible?" European Economic Review, 45, 1851 - 980.

Lopopolo, R. B., Schafer, S. D. \& Nosse, L. J. (2004) "Leadership, administration, management and professionalism (LAMP) in physical therapy: A delphi study", Physical Therapy, 84, 137.

Mickan, S. M. \& Boyce, R. A. (2006) "Organisational change and adaptation in health care", M.G., Harris \& Associates (Eds.), Managing Health Services: Concepts and Practice. Sydney, Moxby Elsevier.

Ormrod, J. (1993) "Decision Making in Health Service Managers", Management Decision, 31, 8.

Rees, D. W. (1996) "The importance of the managerial hybrid", Industrial and Commercial Training, 28, 5.

Schafer, W. E., Park, J. L. \& Woody, M. L. (2002) "Professionalism, organizationalprofessional conflict and work outcomes. A study of certified management accountants", Accounting, Auditing \& Accountability Journal, 15, 46-68.

Smithson, J. \& Stokoe, E. H. (2005) "Discourses of work-life balance: negotiating 'genderblind' terms in organisations", Gender, Work and Organisation, 12, $147-68$.

van de Vliert, E. (1981) "A three-step theory of role conflict resolution". Journal of Social Psychology, 113, 77-83. 